\title{
FORMATION OF TiO 2 PHOTOANODES BY SIMULTANEOUS ELECTROPHORETIC DEPOSITION OF ANATASE AND RUTILE PARTICLES FOR PHOTOASSISTED ELECTROLYTIC COPPER IONS REMOVAL
}

\section{Yeimmy Y. Peralta-Ruiz, Erika M. Lizcano-Beltrán, D. Laverde, Próspero Acevedo-Peña* and Elcy M. Córdoba}

Grupo de Investigaciones en Minerales Biohidrometalurgia y Ambiente, Universidad Industrial de Santander, Calle 9 Cra. 27, Postal code 678, Bucaramanga (Santander), Colombia

Recebido em 19/4/11; aceito em 16/9/11; publicado na web em 8/11/11

\begin{abstract}
The influence of Anatasa/Rutile ratio on $\mathrm{TiO}_{2}$ films, grown by electrophoretic deposition was studied in the photoassisted electrolytic copper ions removal from cyanide solutions. The proper dispersant dosage allowing the simultaneous electrophoretic deposition of Anatase and Rutile was chosen based on electrokinetic measurements; evidenced by the XRD spectra of the formed films. The evaluation of films photoassisted electrolytic copper ion removal showeds that it is possible to enhance the activity of Anatase films by adding some Rutile exploiting the synergetic interaction between these two materials, achieve by its proper deposition.
\end{abstract}

Keywords: electrophoretic multicomponent deposition; photoassited electrolysis; $\mathrm{Cu}$ ions removal.

\section{INTRODUCTION}

$\mathrm{TiO}_{2}$ is believed to be the most promising currently known semiconductor material for photocatalytic and photoelectrolytic applications, thanks to its virtually unique properties including superior photoreactivity, nontoxicity, long-term stability, and low cost. The photocatalytic activity of $\mathrm{TiO}_{2}$ depends on various parameters, including crystallinity, impurities, surface area, and density of surface hydroxyl groups. However, the most significant factor is its crystal form..$^{1-5}$

One $\mathrm{TiO}_{2}$ commercial presentations, known for its high activity, is Degussa P25; ${ }^{2}$ whose high performance, even better than most of the laboratory - made photocatalyst, has been the principal focus of study of a number of different investigations. ${ }^{4-15}$ The superior photocatalytic activity of Degussa P25 has been attributed to differences between the Anatase and Rutile conduction band edge (about 0.2 eV higher). This energy barrier not only allows interfacial electron transfer between these two crystalline phases, but also suppresses electron transfer avoiding its recombination. Consequently, the holes in the valence band of anatase are consumed in the oxidation of some species in solution, while the electrons moving from the conduction band of the anatase toward that of the Rutile are consumed in the reduction reaction.

Great efforts have been made to exploit the interaction between two semiconductors, and to obtain materials with improved performance for application in photoelectrochemical cells. ${ }^{16}$ Recently, Kwan and Chen ${ }^{17}$ have shown the possibility of improving $\mathrm{TiO}_{2}$ films reactivity throughout the interaction of two different crystalline phases, in this case Brookite and Anatase, whose mechanism is similar to that outlined previously for Anatase and Rutile.

The most common route to obtain an Anatase and Rutile mix is through heat treatments of $\mathrm{TiO}_{2}$ films, allowing the formation of Anatase and Rutile crystals within them. ${ }^{2,7-9,12,15}$ However, a sintering temperature increase not only causes the Anatase/Rutile ratio to change within the film but it will also augment crystallites size and lead to a reduction in porosity and surface area of the film. ${ }^{2}$ As the variation of these parameters can also alter the performance of the film, their modification could mask the real effect of the Anatase-Rutile interaction within the material.

\footnotetext{
*e-mail: prosperoacevedopena@yahoo.com
}

The route employed to obtain the $\mathrm{TiO}_{2}$ films seems to be crucial to exploiting the synergistic Rutile and Anatase interaction. Kent-Kho et al. have shown the differences in the photoelectrochemical characterization and photocatalytic hydrogen evolution onto $\mathrm{TiO}_{2}$, composed by mixing Anatase and Rutile. ${ }^{5}$ The synergistic behavior was only found in photocatalytic tests, being absent during photoelectrochemical evaluation since the applied potential renders the interparticle charge separating mechanism less important. However, Jiang et al. have documented this enhanced behavior yielded by the combination of Anatase and Rutile within the $\mathrm{TiO}_{2}$ films. ${ }^{12}$ Since the former grew the films by applying the Dr. Blade technique whereas the latter employed a sol-gel route; the procedure employed for films formation seems to be the underlying cause of the differences, showing the necessity of employing a method that allows intimate contact between the particles within the film.

Electrophoretic deposition has been shown to be an effective alternative for $\mathrm{TiO}_{2}$ films preparation. ${ }^{18,19}$ Additionally, this technique offers the simultaneous and homogeneous growth of multicomponent films, allowing the deposition of different materials without altering physicochemical properties. ${ }^{20-23}$ With this methodology, commercial materials can be used to form films with tailored properties, improving photo-reactivity. Additionally, different parameters such as deposited mass and film thickness formed, can be easily controlled. ${ }^{20}$

To the best of our knowledge, no specific study on improving the photoanode performance through simultaneous and homogeneous electrophoretic deposition of different crystalline phases of $\mathrm{TiO}_{2}$, has been previously reported. This text describes the formation of $\mathrm{TiO}_{2}$ films with different Anatase/Rutile ratios grown by electrophoretic deposition derived from Anatase and Rutile $\mathrm{TiO}_{2}$ commercial powders as raw materials. The adequate dosage of dispersant (Tiron) for preparing a suspension able to allow simultaneous and homogeneous deposition of the materials, was chosen based on electrokinetic measurements of Anatase and Rutile diluted suspensions. The presence and ratio of these two crystalline phases in the film was verified by XRD. The films obtained were evaluated in the photoassisted electrolytic copper ion removal from cyanide solutions, given the harmful nature of the ions and the values which can be recovered from these wasted solutions. A synthetic effluent simulating a real effluent from a galvanoplastic company in the metropolitan area of Bucaramanga city was employed. 


\section{EXPERIMENTAL}

\section{Electrokinetic measurements}

Commercial $\mathrm{TiO}_{2}$ powders (Anatase from Distrimerck and $\mathrm{Ru}-$ tile from Leon laboratories) were employed in this study. The adequate dosage of dispersant $\left(\mathrm{C}_{6} \mathrm{H}_{4} \mathrm{O}_{8} \mathrm{~S}_{2} \mathrm{Na}_{2}, 4,5\right.$-Dihydroxy-1,3-Benzenedisulfonic acid disodium salt), was determined by performing electrokinetics measurements on a Zeta-Meter 3.0+ device. The suspensions employed for the tests constituted $100 \mathrm{mg}$ of $\mathrm{TiO}_{2}$ in $1 \mathrm{~L}$ of a solvent composed by $5.0 \% \mathrm{v} / \mathrm{v} 2$-propanol and distilled water. ${ }^{18,19}$ For the measurements of electrophoretic mobility $(\mu)$ versus $\mathrm{pH}, 0.1 \mathrm{M} \mathrm{NaOH}$ and $\mathrm{HCl}$ solutions were used to change the $\mathrm{pH}$ of the suspensions. The evaluation of the dispersant effect in $\mu$ of $\mathrm{TiO}_{2}$ particles was carried out for a concentration range of between 0.0 and $1.0 \% \mathrm{w} / \mathrm{w}$.

Aliquots of $25 \mathrm{~mL}$ taken from the suspensions of Anatase or Rutile were placed inside a quartz capillary tube, and a potential of $75 \mathrm{~V}$ applied between the Molybdenum anode and Platinum Cathode. Following a stabilization period, the electrophoretic mobility of the particles was estimated using an optical microscope. Electrophoretic mobility corresponds to the distance/time ratio at which the particles move within the cell once the electrical field has been applied. Each point in the electrophoretic mobility vs. $\mathrm{pH}$ curves is the average of 25 measurements, and each point in the electrophoretic mobility vs. Tiron dosage curves is the average of 100 measurements. All measurements were carried out at room temperature $\left(23^{\circ} \mathrm{C}\right)$.

\section{Sedimentation measurements}

The stability of the aqueous suspensions was studied by means of a sedimentation experiment. The suspensions prepared with various dosages of Tiron were placed into sealed graduated test tubes and the heights of the sediments measured with time for a period of $30 \mathrm{~min}$.

\section{Electrophoretic deposition of $\mathrm{TiO}_{2}$ films}

Stainless steel foils (AISI SAE 304), polished with 1200 grade silicon carbide grids were employed as substrates. The foils were cleaned by placing them in an ultrasonic bath with distilled water for $15 \mathrm{~min}$, then in ethanol for $15 \mathrm{~min}$, and finally, in a $0.01 \mathrm{M} \mathrm{NaOH}$ solution for $4 \mathrm{~min}$. After this procedure, the foils were air dried and kept in a desiccator.

$\mathrm{TiO}_{2}$ suspensions were prepared by mixing $10 \mathrm{~mL}$ of a $5.0 \%$ v/v of 2-propanol (J.T. Baker 99.97\%) and distilled water, with 500 $\mathrm{mg}$ of $\mathrm{TiO}_{2}$, in an ultrasonic bath for $10 \mathrm{~min} .^{18,19,24}$ The quantity of Anatase and Rutile added was $500 \mathrm{mg}$, but the Anatase fraction in the powders was changed $(1.0,0.8,0.7,0.5,0.0)$. As the $\mathrm{TiO}_{2}$ acquire a negative surface charge in the suspension, the stainless steel foils, employed as substrates for the films, were used as anodes while another stainless steel foil was used as a cathode. Both foils were set at $2 \mathrm{~cm}$ and parallel to each other. The deposition was carried out in a manner similar that reported in earlier studies, reported before ${ }^{18,19}$ but in this case, a field of $6 \mathrm{~V} / \mathrm{cm}$ for $40 \mathrm{~s}$ was applied. After the electrophoretic deposition of $\mathrm{TiO}_{2}$ particles, the films were withdrawn from the suspensions and dried in a desiccator. The films were subsequently sintered at a temperature of $450^{\circ} \mathrm{C}$ for a $30 \mathrm{~min}$ period. During this process the crystalline phases and particle size remained unchanged. ${ }^{24}$ Crystalline phase composition of the raw materials and prepared films was determined by powder X-ray diffraction (XRD) at room temperature using a Rigaku D/MAX-IIIB difractometer with $\mathrm{Cu} \mathrm{K} \alpha$ radiation. The deposition process was repeated several times in order to collect sufficient sample for the measurement.

\section{Photo-assisted electrolytic copper ions removal}

In the photo-assisted electrolytic copper ion removal tests, the $\mathrm{TiO}_{2}$ films were employed as anodes and a copper foil employed as the cathode. The illumination of the $\mathrm{TiO}_{2}$ films was done through a window within the electrolysis cell, using an UV-Pen ray Hg lamp. To avoid the overheating of the lamp, the unit was inserted in a water jacket of quartz. The synthetic solutions were prepared with a 3:1 molar ratio of cyanide and copper, a copper concentration of $700 \mathrm{ppm}$ $\mathrm{Cu}^{+}$and a $\mathrm{pH}$ of 11.5. This solution represented a typical effluent from a Colombian electrowinning company. For the photoelectrolysis tests, a potential between the anode and cathode of $2.4 \mathrm{~V}$ was applied for $1 \mathrm{~h}$. The copper concentration was measured before and after each test by atomic absorption spectroscopy.

\section{RESULTS AND DISCUSSION}

\section{Characterization of raw materials}

The $\mathrm{TiO}_{2}$ employed to form the films by electrophoretic deposition (EPD) was characterizated by XRD to verify the crystalline phases present in the materials, and by BET measurements to estimate surface area of each sample. Both materials comprised only one crystalline phase, Anatase for Distrimerck- $\mathrm{TiO}_{2}$ and Rutile for Laboratorios León- $\mathrm{TiO}_{2}$, whose principal diffraction angles were 25.4 and $27.8^{\circ}$, respectively. Furthermore, due to the low specific surface area of the materials $\left(8.6 \mathrm{~m}^{2} / \mathrm{g}\right.$ for the Anatase, and $11.4 \mathrm{~m}^{2} / \mathrm{g}$ for the Rutile), it can be expected that they are composed of relatively large particles, in the order of hundreds of nanometers (179 and $124 \mathrm{~nm}$, respectively). This kind of materials has shown to have good photoelectrochemical perfomance, even higher than nanoparticles, given the reduction in the traps related to the grains, and also because larged sized particles are able to support a surface space layer, contributing toward the separation of charier transport photogenerated in the material. ${ }^{25}$ Moreover, owing to the similar surface area of the materials, significant changes in the surface area of the photoanode are not expected, when $\mathrm{TiO}_{2}$ films with mixed crystalline phased are prepared from this materials.

To achieve simultaneous and homogeneous deposition of the two $\mathrm{TiO}_{2}$ materials, certain conditions are required for the suspension, namely: it must be stable; the particles must have high electrophoretic mobility $(\mu)$; it must have adequate conductivity that allows uniform deposit formation, and the $\mu$ of each component must be similar, and thus the ratio of the different components in the obtained film. ${ }^{20-23} \mathrm{To}$ select the composition of the solvent able to fulfill these conditions, electrokinetic measurements were performed for these materials. ${ }^{26}$

\section{Selection of the appropriate dosage of dispersant}

As a first approach to obtain a suitable suspension of Anatase and Rutile for multicomponent EPD, the electrophoretic mobility $(\mu)$ of $\mathrm{TiO}_{2}$ particles was measured in a $5 \% \mathrm{~V} / \mathrm{V}$ of 2-propanol aqueous solution. The $\mu$ values represent an indirect measurement of the exccess surface charge of the suspended material. The higher the $\mu$ values, the better the stability of the colloid in the solvent attained. ${ }^{26}$ In Figure 1, the $\mu$ curves obtained for Anatase and Rutile are shown as a function of the $\mathrm{pH}$ in solvent. The $\mathrm{pH}$ value for a null $\mu$ is the isoelectric point (IEP) of the material. For $\mathrm{pH}$ values higher than IEP, the excess surface charge of the particles is positive, while for lower $\mathrm{pH}$ values are negatives. Across almost the whole $\mathrm{pH}$ range evaluated, the absolute $\mu$ value for the Anatase was higher than that of Rutile, indicating greater stability of the material through electrostatic interactions. However, for simultaneous and homogeneous EPD of these two materials, $\mu$ values of the particles in suspension must be similar where this can 
only be achieved at a pH value where the $\mu$ (an indirect measure of excess surface charge) is not high enough to maintain $\mathrm{TiO}_{2}$ particles in suspension. For this reason, to obtain a stable suspension it was necessary to add a dispersant within the suspensions. As the particles have a negative excess surface charge, an anionic surfactant which has been found to be efficiently adsorbed onto oxides surfaces, was chosen (Tiron: $\mathrm{C}_{6} \mathrm{H}_{4} \mathrm{O}_{8} \mathrm{~S}_{2} \mathrm{Na}_{2}$, 4,5-Dihydroxy-1,3-Benzenedisulfonic acid disodium salt). ${ }^{27,28}$

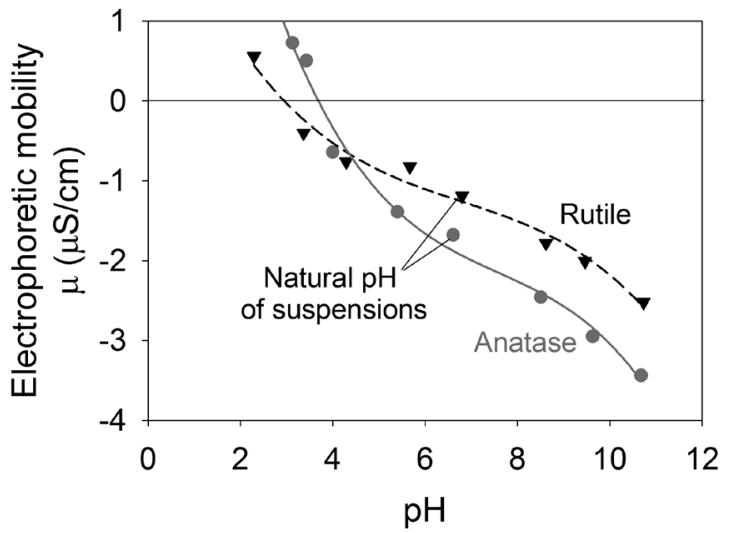

Figure 1. Electrophoretic mobility $(\mathrm{mS} / \mathrm{cm})$ vs $\mathrm{pH}$ curves obtained for the employed materials

To avoid an increase in conductivity, evaluation of the Tiron dosage carried out at the natural $\mathrm{pH}$ of each material suspension. The natural $\mathrm{pH}$ of the prepared suspensions proved very similar, with values of 5.6 and 5.8 for the Anatase and Rutile suspensions, respectively. The mechanism increasing the exccess surface charge has been proposed as being due to the specific adsorption of Tiron over the $\mathrm{TiO}_{2}$ surface, through the $-\mathrm{OH}$ groups, leading to an increase in excess negative surface charge owing to its $-\mathrm{SO}^{3-}$ groups. ${ }^{27,28}$ The changes in the materials $\mu$ by adding different Tiron dosages are showed in the Figure 2.

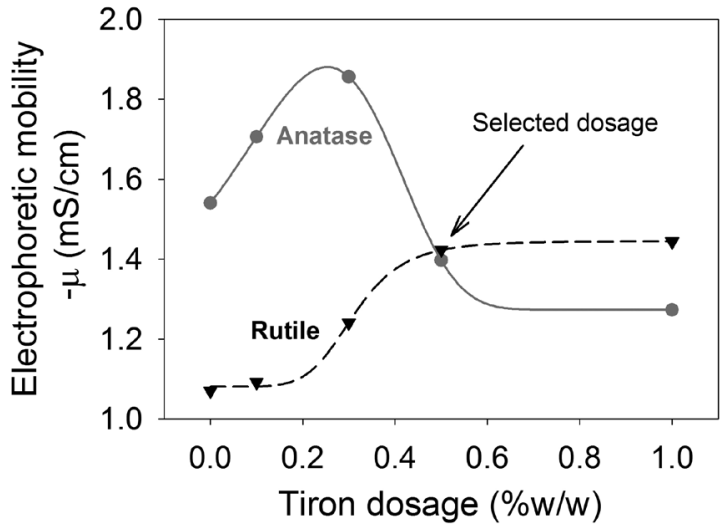

Figure 2. Variation of the electrophoretic mobility $(\mathrm{mS} / \mathrm{cm})$ for Anatase and Rutile, as a function of Tiron dosage

Without Tiron the $-\mu$ values were very different for Anatase and Rutile. Adding a small quantity of Tiron to the solvent lead to an increase in the $-\mu$ values for both materials. The change is considerably greater for Anatase, showing an easier adsorption over this material. For this reason, the $-\mu$ values remain different. For a $0.3 \%$ w/w concentration of Tiron, the excess surface charge of Anatase reaches a maximum. Thereafter, the values for Anatase begin to decrease as its surface becomes saturated with adsorbed Tiron. The increase in dispersant in the solution serves only to enhance the ionic strength of the solution, causing a decrease in the values as a result of the thinning of the electric double layer. On the other hand, the increase in Tiron for the Rutile suspension further increases its $-\mu$ values and stability. When a concentration of dispersant of $0.5 \% \mathrm{w} / \mathrm{w}$ is reached, the $-\mu$ values for both materials match, with this value established as the adequate dispersant dosage for the simultaneous and homogeneous electrophoretic deposition of these two materials. For higher Tiron dosages, the $-\mu$ values are slightly different, becoming higher for Rutile and lower for Anatase.

The measurement of the height of suspensions sediment has been shown to be a reliable and easy method of evaluating its stability. ${ }^{28}$ The technique is commonly employed in conjunction with electrokinetic measurements, because this offers an alternative to evaluating suspension stability under real conditions (solid concentration in our case). Figure 3 shows the results for the sedimentations tests done on Rutile and Anatase suspension $\left(50 \mathrm{gL}^{-1}\right)$. In this case, the stability of the suspension was evaluated by measuring the height of the sediment particles with time, employing a graduated test tube. The greater the height of the sediment, the lower the stability of the suspension is. In general, the Anatase suspensions showed better stability compared with Rutile suspensions. In the case of Anatase, the adding of dispersant to the suspension improved its stability, but beyond a dosage of $0.5 \% \mathrm{w} / \mathrm{w}$ the particles were destabilized. Regarding the Rutile suspension, the addition of dispersant consistently showed suspension stability improvement. However, the best results were also obtained for a dosage of $0.5 \% \mathrm{w} / \mathrm{w}$. These tests confirm the results obtained from the electrokinetic measurements.

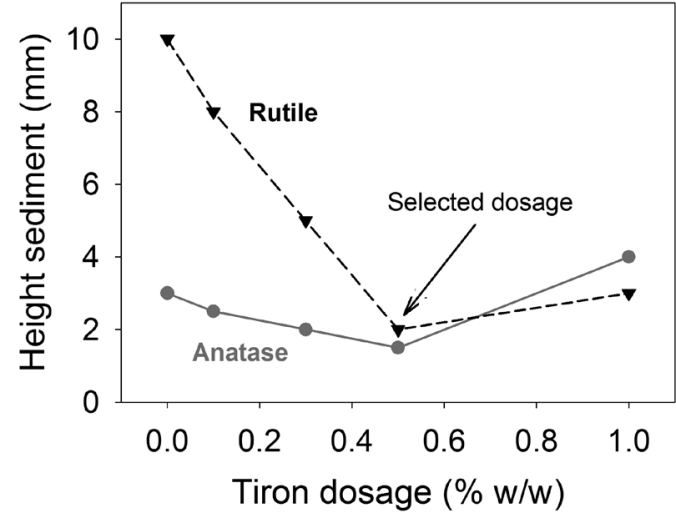

Figure 3. Height of the sediment ( $\mathrm{mm}$ ) as a function of Tiron dosage, for suspensions (50 $\left.\mathrm{g} \mathrm{L}^{-1}\right)$ of Anatase and Rutile

\section{Electrophoretic deposition of $\mathrm{TiO}_{2}$ films}

Once the suspension had beens selected, which satisfies all the condition for the simultaneous and homogeneous electrophoretic deposition of multicomponents, the next step was the deposition of the $\mathrm{TiO}_{2}$ films with mixes of Anatase and Rutile. The procedure employed for film formation was similar to that reported previously in the literature. ${ }^{18,19,24} \mathrm{TiO}_{2}$ films were electrophoretically formed over a substrate of stainless steel (AISI-SAE 304) from a suspension with $30 \%$ solids and a $0.5 \%$ w/w Tiron dosage. The Anatase and Rutile ratio in the suspension was changed in order to obtain films with different mixes of these two crystalline phases. The presence and percentage of these materials was corroborated through XRD measurements, which were taken for the sample deposited over the substrate. Figure 4 shows the difractograms obtained for each deposited film. The peak of Anatase, at $25.4^{\circ}$, falls as the percentage of Anatase in the suspension becomes lower. Conversely, the peak of Rutile, at $27.8^{\circ}$, increases in height. 


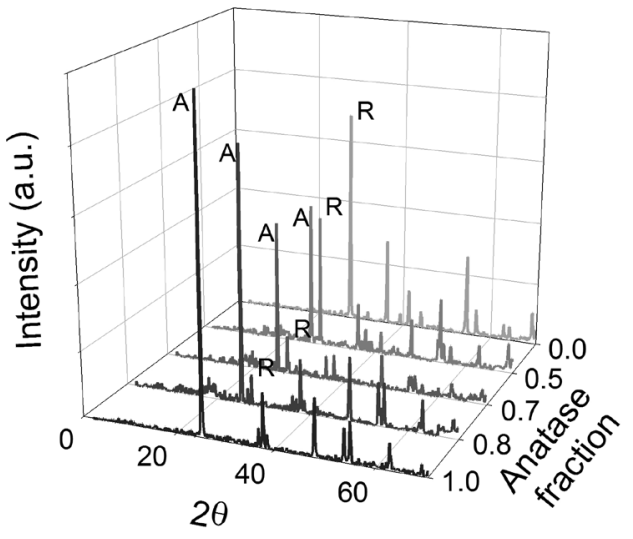

Figure 4. XRD spectra obtained for the $\mathrm{TiO}_{2}$ films electrophoretically deposited from suspensions with different fraction of Anatase

The relationship in peak intensities for Anatase and Rutile allows, the relationship between these two phases in the formed film to be obtained employing Equation 1:9

$$
\mathrm{X}_{\overline{\mathrm{A}}} \frac{1}{1+1.265 \frac{\mathrm{I}_{\mathrm{R}}}{\mathrm{I}_{\mathrm{A}}}}
$$

where $X_{A}$ is the fraction of Anatase in the film, $I_{A}$ is the intensity of the peak attributed to the Anatase $\left(25.4^{\circ}\right)$, and $I_{R}$ is the intensity of the peak attributed to Rutile $\left(27.8^{\circ}\right)$.

Table 1 shows the relationship between the Anatase fraction in the film, estimated from Equation 1, and the Anatase fraction in the suspension. A straight line can be drawn through the points, with a slope very close to unity, showing almost the same Anatase/Rutile relationship in the suspension as in the formed films. This was achieved as a result of the systematic study carried out with the $\mu$ measurements and sedimentation tests. Additionally, previous studies have revealed that by selecting the appropriate conditions for the simultaneous deposition of different materials, films with homogenous distribution of the components can be obtained. ${ }^{20}$ For this reason, we also expected the formed films to have a highly homogeneous distribution of Anatase and Rutile, and exhibit no concentration gradients or spots of one of the materials inside a matrix of the other.

Table 1. Anatase:Rutile ratio in the $\mathrm{TiO}_{2}$ films, estimated from weight and DRX

\begin{tabular}{cc}
\hline \multicolumn{3}{c}{ Anatase:Rutile ratio } \\
\hline From weight & From DRX \\
\hline $100: 0$ & $100: 0$ \\
$80: 20$ & $81: 19$ \\
$70: 30$ & $71: 29$ \\
$50: 50$ & $46: 54$ \\
$0: 100$ & $0: 100$ \\
\hline
\end{tabular}

\section{Photo-assisted electrolytic copper ions removal}

Removal of metal ions from contaminated effluents has received attention due to the feasibility of recovering valuable metals. ${ }^{29-31}$ Photocatalysis has been shown to be an attractive alternative, and using $\mathrm{TiO}_{2}$ particles in suspension has achieved promising results. ${ }^{32-34}$ The metal ions present in effluents are usually found complexed by substances such as EDTA or Cyanide, species widely used in indus- trial applications. The photocatalytic treatment of these solutions has shown several problems where the oxidation of the EDTA is achieved, the reduction of metal ions is not attained ${ }^{30}$ or when cyanide complexes are present. Normally, in order to add a hole scavenger (generally an alcohol), it is necessary to enhance the reduction of the metal complex, thereby inhibiting the oxidation of $\mathrm{CN}^{-}$, resulting in an undesirable accumulation of toxic species in the solution. ${ }^{29}$

Although the results obtained with particulate materials have shown that the heterogeneous photocatalysis is a promising alternative of remediation for this type of effluent, findings have also revealed disadvantages related with the separation, recovery and recycling of the catalyst and metallic deposits from the treated effluents. ${ }^{29-34}$ An alternative and effective methodology to overcome these inconveniences is photoassisted electrolysis. ${ }^{35}$ With this technique, the $\mathrm{TiO}_{2}$ is supported on a conductive substrate to be used as the anode and coupled with a conductive material acting as a cathode. In this methodology the metal ions are reduced over a metallic electrode allowing its recovery, or facilitating its disposal. Additionally, thanks to the imposed potential, the oxidation of the complexing agent can occur at the photoanode, avoiding the addition of hole scavengers to the solution.

The synthetic effluent used for the photo-reactivity evaluation of the $\mathrm{TiO}_{2}$ films obtained has cyanide to copper of ratio 3:1, with a copper concentration of $700 \mathrm{ppm}$ and a $\mathrm{pH}$ of 11.5. Under these conditions, the principal cyanide complex present in the solution is $\mathrm{Cu}(\mathrm{CN})_{3}^{2-} .^{36}$ For this reason, the reduction of copper is expected to occur through the following reaction:

$$
\mathrm{Cu}(\mathrm{CN})_{3}^{2-}+e^{-} \rightarrow \mathrm{Cu}^{0}+3 \mathrm{CN}^{-}
$$

However, due to the negative potential required for the reduction of this complex, the hydrogen evolution from water, Reaction 2, will be also present during the process, consuming part of the photogenerated electrons from the $\mathrm{TiO}_{2}$

$$
2 \mathrm{H}^{+}+2 e^{-} \rightarrow H_{2}
$$

The anodic reactions implied in the process are the oxidation of $\mathrm{OH}^{-}$and $\mathrm{CN}^{-}$ions present in solution, which can scavenge the $h^{+}$ from the $\mathrm{TiO}_{2}$, thus diminishing recombination with photogenerated electrons. ${ }^{37}$

$$
\begin{gathered}
\mathrm{CN}^{-}+2 \mathrm{OH}^{-}+2 \mathrm{~h}^{+} \rightarrow \mathrm{CNO}^{-}+\mathrm{H}_{2} \mathrm{O} \\
4 \mathrm{OH}^{-}+4 h^{+} \rightarrow \mathrm{O}_{2}+2 \mathrm{H}_{2} \mathrm{O}
\end{gathered}
$$

Additionally, given the high oxidant potential of the holes in the $\mathrm{TiO}_{2}$, the complete mineralization of the cyanide is expected, leaving the effluent free of this dangerous pollutant.

$$
2 \mathrm{CNO}^{-}+8 \mathrm{OH}^{-}+6 h^{+} \rightarrow 2 \mathrm{CO}_{3}^{2-}+\mathrm{N}_{2}+4 \mathrm{H}_{2} \mathrm{O}
$$

The percentage of $\mathrm{Cu}$ removed was determined by measuring the concentration of $\mathrm{Cu}$ before and after each experiment using the atomic absorption technique. Figure 5 shows the $\%$ of $\mathrm{Cu}$ removed as a function of the fraction of Anatase in the film, for the experiments carried out in the dark ( $\nabla$ Light off) and under illumination ( $\Delta$ Light on). The difference between the copper ion remotion under illumination and in the dark is also shown, indicating the effect of light $(\bullet)$. When the electrolytic copper removal tests were carried out in the dark (Light off), there was no relationship between the presence of Anatase in the film and the copper removal from the solution. However, when these tests were carried out under illumi- 
nation (Light on), a marked influence of Anatase on the percentage of copper removed was observed, reaching higher percentages of copper removal from the solution. Furthermore, the filled circles, which only reflect the effect of the light, clearly showed a synergistic effect between Anatase and Rutile, which leads to an increase in the activity of the films. Nevertheless, as reported for particles in suspension, this effect was only observed at high Anatase fractions in the film, after which the film activity decreases, due to the high recombination losses in Rutile..$^{5-15}$

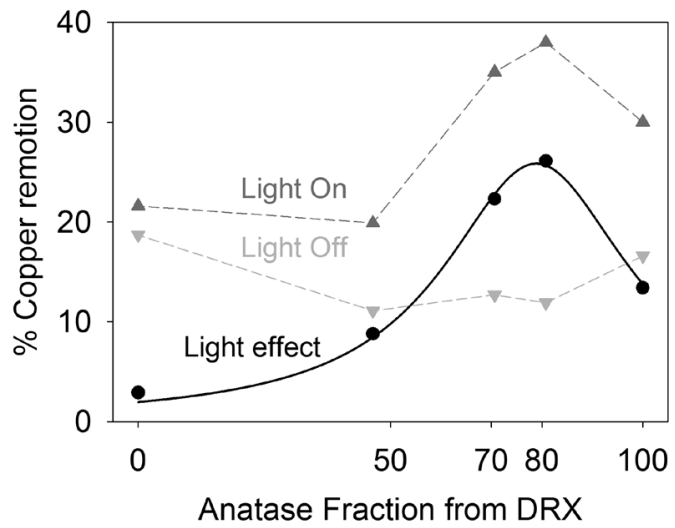

Figure 5. Effect of the ratio Anatase/Rutile in the film on the copper removal, in the dark $(\nabla)$ and under illumination $(\mathbf{\Delta})$. The effect of the illumination over the copper removal is also showed in the figure (

Given the proper preparation of the suspension, the Rutile within the films was evenly distributed over them; and because sintering of the film creates contact between the particles allowing $e^{-}$transport, the synergistic effect between Anatase and Rutile (Figure 5) is observed in the formed films. The separation of the charge carriers is improved due to the small difference in the position of the bands in these materials $(0.2 \mathrm{eV})$, which allows efficient separation of photogenerated carriers within the Anatase (Figure 6 inset). ${ }^{4-15}$ The photogenerated holes in Anatase are readily transferred to a species in suspension. Thus, the electrons are transported toward the back contact through the particles surface states, Figure $6 .{ }^{4}$ However, by decreasing the fraction of Anatase in the film, most charge carriers are photogenerated in the Rutile particles, and since the oxidation reaction on the Rutile surface is slower than that of Anatase, ${ }^{4}$ the residence time of the two carriers in the particles is increased. Consequently, frequency of recombination also increases, negatively impacting the photoelectrochemical performance of the $\mathrm{TiO}_{2}$ films.

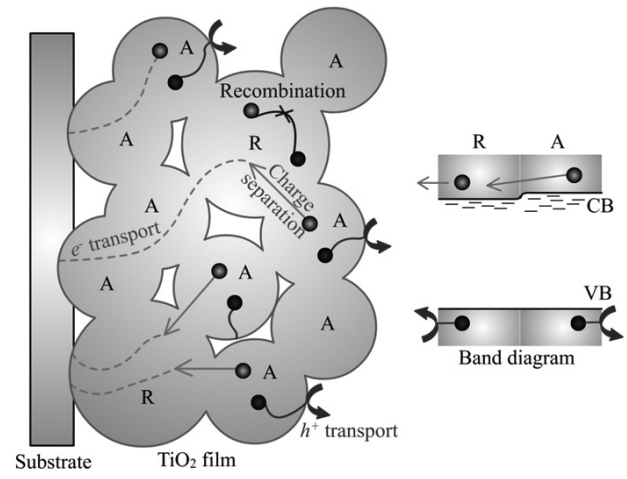

Figure 6. Schematization of the role played by the Rutile particles over the separation of the photogenerated carries in the film. The insert shows the band diagrams for the Anatase and Rutile: the energetic differences between them, facilitates the separation of charge carriers in the Anatase

\section{CONCLUSION}

The results obtained in this study show that it is possible to tailor the activity of photoanodes composed by mixed materials, by properly selecting the dispersant dosage to allowing the simultaneous electrophoretic deposition of the photocatalyst. Addittionally, electrophoretic deposition proved to be an adequate methodology for preparing photoanodes with enhanced activity, derived from commercial materials. In the present study, the known synergetic interaction between Rutile and Anatase was exploited to improve $\mathrm{TiO}_{2}$ films activity.

\section{ACKNOWLEDGEMENTS}

This work has been given the financial support from COLCIENCIAS (Project 1102-521-28875) and Universidad Industrial de Santander, UIS (DIEF Ingenierías Fisicoquímicas, Project No. 5430). The authors are grateful with the Dr. L. Henao from UIS, for the X-ray diffraction measurements.

\section{REFERENCES}

1. Bertazzoli, R.; Pelegrini, R.; Quim. Nova 2002, 25, 477.

2. Machado Fernandes, N. R. C.; Santana, V. S.; Catal. Today 2005, 107-108, 595 .

3. Brunelli, T. F. T.; Guaraldo, T. T.; Paschoale, F. M. M.; Zanoni, M. V. B.; Quim. Nova 2009, 32, 67.

4. Bilecka, I.; Barczuk, P. J.; Augustynski, J.; Electrochim. Acta 2010, 55, 979.

5. Kho, Y. K.; Iwase, A.; Teoh, W. Y.; Mädler, L.; Kudo, A.; Amal, R.; J. Phys. Chem. C 2010, 114, 2821.

6. Emeline, A. V.; Smirnova, L. G.; Kuzmin, G. N.; Basov, L. L.; Serpone, N.; J. Photochem. Photobiol. A 2002, 148, 97.

7. Ohno, T.; Tokieda, K.; Higashida, S.; Matsumura, M.; Appl. Catal. A 2003, 244, 383.

8. Sun, B.; Smirniotis, P. G.; Catal. Today 2003, 88, 49.

9. Wu, C.; Yue, Y.; Deng, X.; Hua, W.; Gao, Z.; Catal. Today 2004, 93-95, 863.

10. Nakajima, H.; Mori, T.; Shen, Q.; Toyoda, T.; Chem. Phys. Lett. 2005, 409,81 .

11. Li, G.; Gray, K. A.; Chem. Phys. 2007, 339, 173.

12. Jiang, D.; Zhang, S.; Zhao, H.; Environ. Sci. Technol. 2007, 41, 303.

13. Chen, X. D.; Wang, Z.; Liao, Z. F.; Mai, Y. L.; Zhang, M. Q.; Polim. Test. 2007, 26, 202.

14. van der Meulen, T.; Mattson, A.; Österlund, L.; J. Catal. 2007, 251, 131.

15. Jing, L.; Li, S.; Song, S.; Xue, L.; Fu, H.; Sol. Energy Mater. Sol. Cells 2008, 92, 1030.

16. Silva, S. S.; Magalhães, F.; Sansiviero, M. T. C.; Quim. Nova 2010, 33, 85.

17. Kang, X.; Chen, S.; J. Mater. Sci. 2010, 45, 2696.

18. Acevedo-Peña, P.; Vázquez, G.; Laverde, D.; Pedraza-Rosas, J. E.; Manríquez, J.; González, I.; J. Electrochem. Soc. 2009, 156, C377.

19. Acevedo-Peña, P.; González, I.; Vázquez, G.; Manríquez, J.; Quim. Nova 2011, 34, 390 .

20. Nagarajan, N.; Nicholson, P. S.; J. Am. Ceram. Soc. 2004, 87, 2053.

21. Wang, Y. H.; Chen, Q. Z.; Cho, J.; Boccaccini, A. R.; Surf. Coat. Technol. 2007, 201, 7645 .

22. Besra, L.; Liu, M.; Prog. Mater. Sci. 2007, 52, 1.

23. Castro, R. H. R.; Kodama, P. K.; Gouvêa D.; Muccillo, R.; J. Mater. Sci. 2009, 44, 1851.

24. Maríquez, J.; Godínez, L. A.; Thin Solid Films 2007, 515, 3402.

25. Kozuka, H.; Takahashi, Y.; Zhao, G.; Yoko, T.; Thin Solid Films 2000, $358,172$. 
26. Zarbov, M.; Schuster, I.; Gal-or, L.; J. Mater. Sci. 2004, 39, 813.

27. Jiang, L.; Gao, L.; Mater. Chem. Phys. 2003, 80, 157.

28. Guedes, M.; Ferreira, J. M. F.; Ferro, A. C.; J. Colloid Interface Sci. 2009, 330, 119.

29. van Grieken, R.; Aguado, J.; López-Muñoz, M. J.; Marugán, J.; Gold Bull. 2005, 38, 180.

30. López-Muñoz, M. J.; Aguado, J.; van Grieken, R.; Marugán, J.; Appl. Catal. B 2009, 86, 53.

31. Park, S.; Hong-Sick, K.; Ju-Hyeon, L.; Youn C. K.; Jae, C. L.; Yun-Joong, C.; J. Eur. Ceram. Soc. 2010, 30, 177.

32. Chen, D.; Ray, A. K.; Chem. Eng. Sci. 2001, 56, 1561.
33. Kanki, T.; Yoneda, H.; Sano, N.; Toyoda, A.; Nagai, C.; Chem. Eng. J. 2004, 97, 77

34. Sharma, S. D.; Saini, K. K.; Kant, C.; Sharma, C. P.; Appl Catal B 2008, $84,233$.

35. Philippidis, N.; Sotiropoulos, S.; Efstathiou, A.; Poulios, I.; J. Photochem. Photobiol., A 2009, 204, 129.

36. Puigdomenech, I.; Medusa (chemical equilibrium software); Royal Institute of Technology (KTH), Sweden, 2004, http://www.kemi.kth.se/ medusa, accessed October 2010.

37. Pedraza-Avella, J. A.; Acevedo-Peña, P.; Pedraza-Rosas J. E.; Catal. Today 2008, 133-135,611. 